\title{
MAPPING RICE CROPPING SYSTEM IN THE LOWER GANGETIC PLAIN USING LANDASAT 8 (OLI) AND MODIS IMAGERY
}

\author{
Arabinda Maiti*, Prasenjit Acharya \\ Department of Geography and Environment, Vidyasagar University, Midnapore, India - maitiarabindageo454@gmail.com
}

Commission V, SS: Natural Resources Management

KEY WORDS: Cropping pattern, rice mapping, MODIS, EVI, LSWI, Crop phenology, Time-series analysis

\begin{abstract}
:
The Indo-Gangetic basin is one of the productive rice growing areas in South-East Asia. Within this extensive flat fertile land, lower Gangetic basin, especially the south Bengal, is most intensively cultivated. In this study we map the rice growing areas using Moderate Resolution Imaging Spectroradiometer (MODIS) derived 8-day surface reflectance product from 2014 to 2015 . The time series vegetation and wetness indices such as Normalized Difference Vegetation Index (NDVI), Enhanced Vegetation Index (EVI) and Land Surface Water Index (LSWI) were used in the decision tree (DT) approach to detect the rice fields. The extracted rice pixels were compared with Landsat OLI derived rice pixels. The accuracy of the derived rice fields were computed with 163 field locations, and further compared with statistics derived from Directorate of Economics and Statistics (DES). The results of the estimation shows a high degree of correlation $(r=0.9)$ with DES reported area statistics. The estimated error of the area statistics while compared with the Landsat OLI was $\pm 15 \%$. The method, however, shows its efficiency in tracing the periodic changes in rice cropping area in this part of Gangetic basin and its neighboring areas.
\end{abstract}

\section{INTRODUCTION}

The Indo-Gangetic basin (IGP) is one of the prominent rice growing areas in South-East Asia. The extensive fertile alluvial plain couple with dense irrigation network and monsoon rain have made this flat alluvia deposit as one of the most productive rice growing regions. The lower Gangetic basin, especially, the south Bengal, in entire IGP, is intensively cultivated with ample varieties of crops. Most of agricultural fields here is triple cropping system with rice as dominant crop (Panigrahy and Upadhyay, 2011). Couple of previous studies showed cropping pattern in IGP and lower Gangetic basin using time series SPOT NDVI data(Panigrahy and Upadhyay, 2011) and combining AWiFS and SAR data (Manjunath et al., 2011). These studies used combination of threshold and unsupervised classification approach to classify crop pixels into different cropping pattern. In this study, however, we tried to use higher time-resolved coarse resolution images to map rice crop pixels. The coarse resolution MODIS and AVHRR images in mapping crop area and cropping patter are widely practiced worldwide (Gumma et al., 2014). The successful commission of these studies in differentiating crops provides the opportunity to use these high frequency (temporal) coarse resolution satellite images in deriving the rice growing fields. The accuracy of the derived rice area is also assessed with respect to the combination of insitu and reported area statistics.

\section{STUDY AREA}

The study area under lower Gangetic plain extends from $21^{\circ} 32^{\prime} 22^{\prime \prime}$ to $25^{\circ} 32^{\prime} 16.97^{\prime \prime} \mathrm{N}$ and $85^{\circ} 49^{\prime} 34.90^{\prime \prime}$ to $89^{\circ} 05^{\prime} 46.91^{\prime \prime}$ E (Figure 1). The topographic characteristics of the area is vast alluvial plain in the central and eastern part, whereas, western part is featured by undulating topography of eastern plateau, called 'Chotonagpur plateau. The western part therefore is drained by the tributaries originated in eastern plateau. The region is dominated by the monsoon climate with periodic wet and dry conditions. The annual average maximum and minimum temperatures are $29.6^{\circ}$ and $21.1^{\circ} \mathrm{C}$, respectively. The monsoon rainfall coupled with well-articulated irrigation network provide conducive environment to grow rice crop in this part of lower Gangetic basin. The average farm size is 0.77 ha (Directorate Economics and Statistics) which is below the national average of 1.15 ha. The high degree of land fragmentation combining with intensive cultivation produces a large variety of cropping patterns. Most of these patterns are triple cropping system with the predominance of rice-rice-rice system.

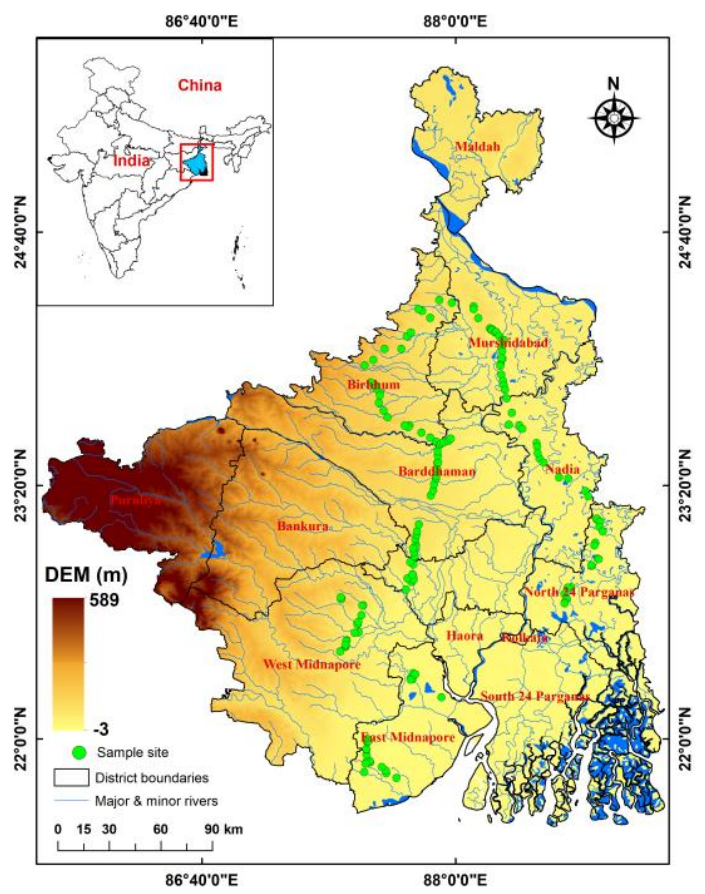

Figure 1. Physical setup of the study area

\footnotetext{
${ }^{*}$ Corresponding author
} 


\section{DATA AND METHODS}

The level-3 8-day composite surface reflectance product of MODIS (MOD09A1) from August 2014 to July 2015 was used. The level-3 surface reflectance products were produced based on the maximum value of the surface reflectance over a period of 8 day. Landsat OLI (level 1B) data for the selective date (2601-2015) at the time of rice transplantation was also used. The time series NDVI, EVI and LSWI were computed from MOD09A1 surface reflectance data (Equation 1-3).

$$
\begin{aligned}
& \mathrm{EVI}=\mathrm{G} \frac{\rho_{\text {nir }}-\rho_{\mathrm{rud}}}{L+\rho_{\text {nir }}+C_{1,} \rho_{\text {red }}+C_{2} \rho_{\text {hlu }}}(1) \\
& \mathrm{NDVI}=\frac{\rho_{\text {nir }}-\rho_{\mathrm{rgd}}}{\rho_{\text {nir }}+\rho_{\mathrm{rgd}}} \\
& \mathrm{LSWI}=\frac{\rho_{\text {swir }}-\rho_{\text {nuiv }}}{\rho_{\text {swir }}+\rho_{\text {nir }}}
\end{aligned}
$$

Where, $\mathrm{C} 1(\mathrm{C} 1=6)$ and $\mathrm{C} 2(\mathrm{C} 2=7.5)$ are the coefficients of the aerosol correction for blue and red band, respectively. $\mathrm{L}$ is the canopy background adjustment $(\mathrm{L}=1)$. $\mathrm{G}$ is the gain factors $(\mathrm{G}=2.5)$. $\rho_{\text {blu }}, \rho_{\text {red }}, \rho_{\text {nir }}$, and $\rho_{\text {swir }}$ are reflectance at blue, red, near infrared and shortwave infrared.

The computed vegetation indices were stack to get time series signals of NDVI, EVI and LSWI. Although level-3 surface reflectance products were generated after removing the cloud and aerosol effects, the residual atmospheric effects are still present in these derived products. To deal with that, we used Savitzky-Golay filter to remove the unexpected spikes in the time signals and to make it smooth (ref). Savitzky-Golay filter used a $2^{\text {nd }}$ order polynomial function (Equation 4) to fit the data in selected time window.

$$
f(\mathrm{t})=\beta_{0}+\beta_{1} \mathrm{t}+\beta_{2} t^{2}
$$

Where, $f(t)$ is fitted value in the selected time window. $\square_{l}$ and $\square_{2}$ are coefficients of the polynomial equation. The smoothed time signals of these vegetation indices were then passed through the DT approach to separate the rice growing areas from other land cover categories. We used standard deviation of time signals in DT to exclude the other land cover categories. Since cultivation of rice is associated with flooding (or water logging) of the fields followed by transplantation at the time of sowing, and mixture of naked soil and rice residue at the time of harvesting, a sequence of LSWI and NDVI were used first during flooding and transplanting phases, whereas EVI was used during maturity and harvesting season. A sum of 163 insitu locations were used to generate standard reference of time series signals of rice growing and other fields. Threshold values in DT were carefully selected based on these standard references. For the purpose of cross checking the results, we computed LSWI and EVI on the Landsat OLI image on the selected date. The time of the acquisition of OLI image was in tune with the transplantation stage of rice. Since transplantation also include the flooding signal, LSWI was subtracted from EVI to get the value greater than 0 for all rice pixels. DT was applied to OLI derived LSWI-EVI index to extract the rice pixels. The difference in estimated rice area from MODIS and OLI was reported. The area statistics derived at each districts were compared further with DES reported rice area.

Based on the field information (start of season (SOS), maximum greenness time (MGT) and end season (EOS)), all of three paddy rice systems are separated from other cropping systems.
Maximum cropland in the study area during Kharif season is used for aman-rice purpose and their SOS start from 20th July to 13th August, MGT from 14th September to 30th September and their EOS time varies from 25th November to 11th December. So, we put a threshold value of EVI $($ EVI > 4) at their maturity time (on 07 October) which easily separate amanrice pixel from other non-crop pixel. In rabi season, considered as the time of maximum crop diversification, the boro-rice separate from others crop pixel based on MGT and EOS with EVI threshold greater than 0.4 on 22 March and less than 0.25 on 01 May, respectively. In this way, amn-rice also separate from other crop and fallow pixel with EVI threshold is greater than 0.4 and less than 0.45 during MGT.

\section{RESULTS AND DISCUSSIONS}

\subsection{MODIS derive Rice Area}

Figure 2 shows samples of standard time series vegetation signals from three different cropping systems. All of these three cropping pattern unanimously show a high LSWI value at the beginning of rice season. LSWI, however, decreases gradually giving way to increase the NDVI and EVI with the physical growth of the rice crop. A notable increase of LSWI is observed again at the peak physical maturity period due to the watering of the agricultural field. Under rice-fallow-fallow system, the EVI and NDVI ranges between $0.18-0.3$ and $0.35-0.5$, respectively after harvesting of first crop. Under double cropping rice-rice-fallow system both NDVI and EVI ranges between $0.18-0.25$ after harvesting of the second crop. In both these cropping systems NDVI and EVI at the peak maturity period reaches up to $0.75-0.8$ and $0.55-0.6$, respectively. However, in triple cropping system such as in rice-rice-rice, the NDVI and EVI at the time of physical maturity of third crop remain well below 0.5 . It happens, perhaps, due to shorter crop cycle coupled with low water availability at the field.

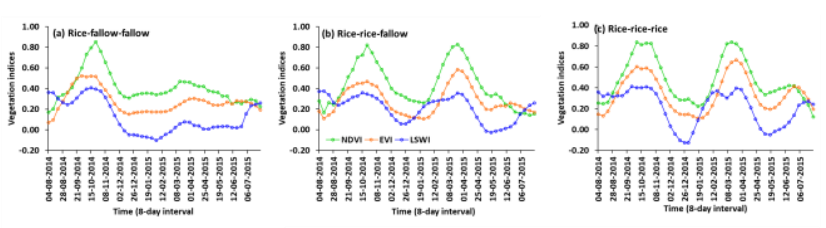

Figure 2. Time series signal of major cropping systems

Apart from these three rice systems we have analyzed other combinations of crops with rice. Using these vegetation indices in DT, all the rice pixels were identified. The spatial distribution of the first rice (Aman) crop (as per crop calendar of south Bengal), shows a wide spread occurrence during kharif season with the onset of monsoon (Figure 3a). MODIS drive aman-rice area is 35919101 ha which $10 \%$ is over estimated as compared to DES reported area (Table 1). In rabi season, i.e. in winter, the rice pixels are concentrated along the central part, however, clusters of rice pixels are also observed in eastern part of the alluvial plain (Figure 3b). The derived area statistics shows about $6.46 \%$ cropland during this season is underestimated with respect to DES reported area (Table 2). During zaid season, i.e. in pre-monsoon season, the rice pixels are agglomerated mostly in southern part (Midnapore) and eastern part (Nadia) (Figure $3 \mathrm{c}$ ). About $1.90 \%$ cropland area during zaid season is underestimated with respect to DES reported area (Table 3). However, some cluster of rice pixels are also observed in 
eastern Bankura and Bardhaman which are belong to the central part of the plain. 135583

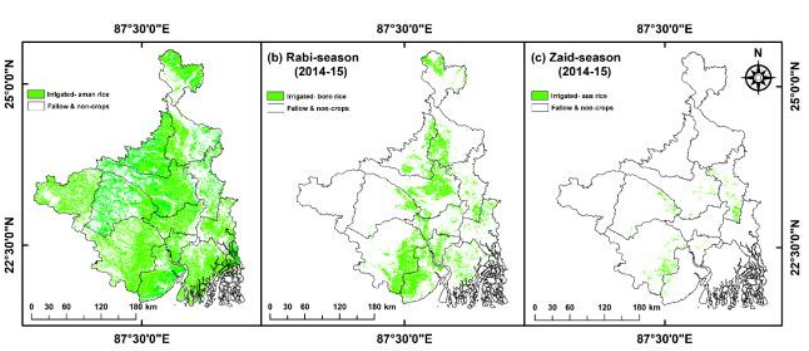

Figure 3. Seasonal and spatial distribution of paddy rice. (a) rice in kharif season, (b) in rabi season and (c) in zaid season

\subsection{Comparison with Landsat OLI derived Rice Area}

Figure 4 shows distribution of EVI (Figure 4a) and LSWI-EVI (Figure $4 \mathrm{~b}$ ) on OLI image. The pixels with values greater than 0 in both EVI and LSWI, and a value less than 0.6 in LSWI comes under rice growing areas (Figure $4 b$ ). The results based on this selected tile of Landsat (Figure 5a) during rabi season show an identical pattern of spatial distribution of rice pixels between MODIS and OLI (Figure 5b, 5c). The distribution of error in area statistics between MODIS and OLI is within $\pm 33 \%$ predominantly (Figure 5d).

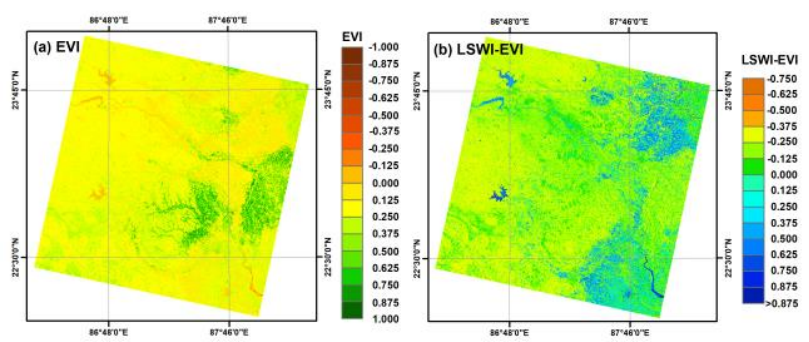

Figure. 4. Landsat OLI drive spatial variation of (a) EVI and (b) LSWI-EVI on 25.01.2015.

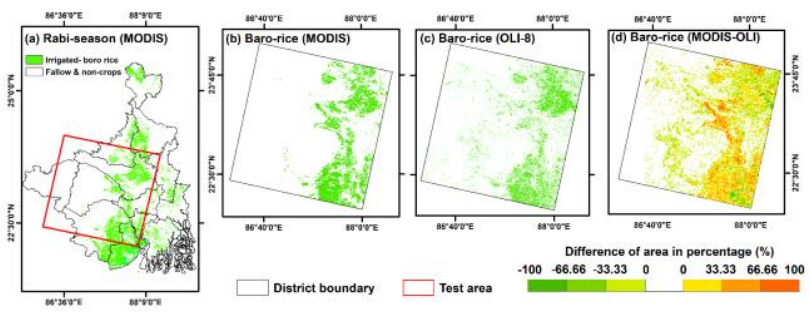

Figure 5. (a) MODIS drive spatial distribution of cropping diversification in rabi season in South Bengal. (b) Boro-rice area estimated from MODIS (c) Boro-rice area estimated from Landsat OLI (c) Percentage of difference between MODIS and OLI in 2014-15.

\subsection{Comparison with DES Statistics}

The comparison of the MODIS derived rice area statistics with DES reported area statistics shows a high degree of correlation with less than $10-15 \%$ of absolute error. The scatterplot in all three seasons (Figure 6) shows a significant positive coefficient (slope) with $R^{2}$ more than 0.8. It is notable, however, that correlation is highest during kharif rice season (Aman rice) and remain comparatively week during rabi rice season (Boro rice). Such discrepancy in the area statistics may happens due to the inherent limitation of the selected algorithm or sometimes due to under-reporting of the actual rice area under each season.
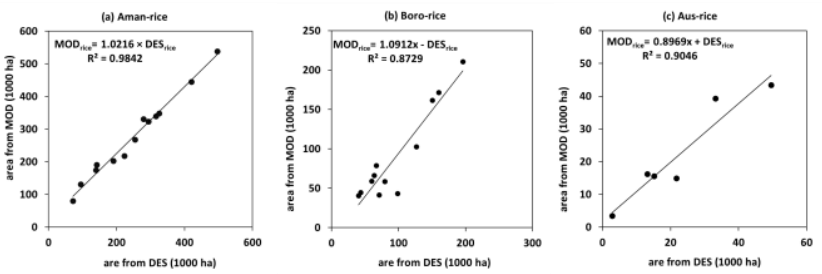

Figure 6. Comparison of area statistics between MODIS and DES reported rice area for (a) aman-rice, (b) boro-rice and (c) aus-rice.

\begin{tabular}{llll}
\hline \multicolumn{1}{c}{ Districts } & \multicolumn{3}{c}{ Aman-rice } \\
\cline { 2 - 4 } & DES & MODIS & Difference (\%) \\
\hline 1.24 PARAGANAS NORTH & 139767 & 174195.5 & 24.63 \\
2.24 PARAGANAS SOUTH & 325501 & 347902.4 & 6.88 \\
3.BANKURA & 294204 & 323696.7 & 10.02 \\
4.BIRBHUM & 315561 & 340096 & 7.78 \\
9.HOOGHLY & 190221 & 203263.9 & 6.86 \\
10.HOWRAH & 71064 & 79660.85 & 12.10 \\
12.MALDAH & 141455 & 190618.7 & 34.76 \\
13.MEDINIPUR EAST & 254064 & 268325 & 5.61 \\
14.MEDINIPUR WEST & 496134 & 538294.7 & 8.50 \\
15.MURSHIDABAD & 222718 & 218245 & -2.01 \\
16.NADIA & 94963 & 131194.9 & 38.15 \\
17.PURBA BARDHAMAN & 419814 & 444987.6 & 6.00 \\
18.PURULIA & 279151 & 331419.6 & 18.72 \\
\hline Total & 3244617 & 3591901 & 10.70 \\
\hline
\end{tabular}

Table 1. Comparison between DES and MODIS rice area (Aman)

\begin{tabular}{llll}
\hline \multicolumn{1}{c}{ Districts } & \multicolumn{3}{c}{ Boro-rice } \\
\cline { 2 - 4 } & DES & MODIS & Difference (\%) \\
\hline 1.24 PARAGANAS NORTH & 70898 & 41332.11 & -41.70 \\
2.24 PARAGANAS SOUTH & 63392 & 66395.96 & 4.74 \\
3.BANKURA & 40185 & 40628.94 & 1.10 \\
4.BIRBHUM & 66581 & 79029.18 & 18.70 \\
9.HOOGHLY & 79654 & 58863.69 & -26.10 \\
10.HOWRAH & 43456 & 44788.37 & 3.07 \\
12.MALDAH & 59802 & 59292.74 & -0.85 \\
13.MEDINIPUR EAST & 159819 & 171513.9 & 7.32 \\
14.MEDINIPUR WEST & 195960 & 210784.2 & 7.56 \\
15.MURSHIDABAD & 126504 & 102627.1 & -18.87 \\
16.NADIA & 98286 & 43393.95 & -55.85 \\
17.PURBA BARDHAMAN & 150267 & 161610 & 7.55 \\
18.PURULIA & & & \\
\hline Total & 1154804 & 1080260 & -6.46
\end{tabular}

Table 2. Comparison between DES and MODIS rice area (Boro)

\begin{tabular}{|c|c|c|c|}
\hline \multirow[t]{2}{*}{ Districts } & \multicolumn{3}{|c|}{ Aus-rice } \\
\hline & DES & MODIS & Difference $(\%)$ \\
\hline PARAGANAS & & & \\
\hline NORTH & & & \\
\hline PARAGANAS & & & \\
\hline SOUTH & & & \\
\hline 3.BANKURA & 21698 & 14945.35 & -31.12 \\
\hline 4.BIRBHUM & & & \\
\hline 9.HOOGHLY & & & \\
\hline 10.HOWRAH & 2836 & 3503.933 & 23.55 \\
\hline 12.MALDAH & & & \\
\hline 13.MEDINIPUR EAST & 15111 & 15565.09 & 3.01 \\
\hline 14.MEDINIPUR WEST & 33141 & 39317.94 & 18.64 \\
\hline 15.MURSHIDABAD & & & \\
\hline 16.NADIA & 49599 & 43393.95 & -12.51 \\
\hline 17.PURBA & 13198 & 16280.18 & 23.35 \\
\hline BARDHAMAN & & & \\
\hline 18.PURULIA & & & \\
\hline Total & 135583 & 133006.4 & -1.90 \\
\hline
\end{tabular}

Table 3. Comparison between DES and MODIS rice area (Aus) 


\section{CONCLUSION}

The analysis reveals a concise method of identification of rice growing areas based on the time series signals of selected vegetation indices. In comparison to the previous studies in this part of IGP that uses high resolution data, the results of this work is indifferent. In some season, such as in kharif season, the degree of association to the reported rice area by DES is much conformable than any of the previous studies. Hence, coarse resolution and high temporal frequency MODIS image can effectively be used in periodic mapping of rice area. Such periodic mapping can also be extended to agricultural policy framing in the era of rapidly growing demands for cereal crop.

\section{ACKNOWLEDGEMENTS}

This study was supported by the research grants from University Grants Commission (UGC). Also thankful to LAADS Web service administered and United-States Geological Survey (USGS) for providing satellite images. We thank to Directorate of Economics and Statistics (DES) for providing crop area statistic in India.

\section{REFERENCES}

Gumma, M.K., Thenkabail, P.S., Maunahan, A., Islam, S., Nelson, A., 2014. Mapping seasonal rice cropland extent and area in the high cropping intensity environment of Bangladesh using MODIS $500 \mathrm{~m}$ data for the year 2010. ISPRS J. Photogramm. Remote Sens. 91, 98-113. doi:10.1016/j.isprsjprs.2014.02.007

Manjunath, K.R., Kundu, N., Ray, S.S., Panigrahy, S., Parihar, J.S., 2011. STUDY OF CROPPING SYSTEMS DYNAMICS IN THE LOWER GANGETIC PLAINS OF INDIA USING GEOSPATIAL TECHNOLOGY. Int. Arch. Photogramm. Remote Sens. Spat. Inf. Sci. XXXVIII, 40-45.

Panigrahy, S., Upadhyay, G., 2011. Mapping of Cropping System for the Indo-Gangetic Plain Using Multi-Date SPOT NDVI-VGT Data. j Indian soc Remote sens 38, 627-632. doi:10.1007/s12524-011-0059-5

Smith, J., 1987a. Close range photogrammetry for analyzing distressed trees. Photogrammetria, 42(1), pp. 47-56.

Smith, J., 1987b. Economic printing of color orthophotos. Report KRL-01234, Kennedy Research Laboratories, Arlington, VA, USA.

Smith, J., 1989. Space Data from Earth Sciences. Elsevier, Amsterdam, pp. 321-332.

Smith, J., 2000. Remote sensing to predict volcano outbursts. In: The International Archives of the Photogrammetry, Remote Sensing and Spatial Information Sciences, Kyoto, Japan, Vol. XXVII, Part B1, pp. 456-469. 